\title{
Characterization of Small-scale Farming Systems in West Kenya and Opportunities for Their Improvement
}

\author{
Paul L. Woomer ${ }^{1, *}$, Canon Norris Savala ${ }^{1}$, Celister Kaleha ${ }^{2}$, Moses Chamwada ${ }^{2}$ \\ ${ }^{1}$ International Institute for Tropical Agriculture (IITA), Kenya \\ ${ }^{2}$ Western Regional Agriculture Technology Evaluation (WeRATE), Kenya
}

Copyright $\mathrm{O} 2016$ by authors, all rights reserved. Authors agree that this article remains permanently open access under the terms of the Creative Commons Attribution License 4.0 International License

\begin{abstract}
Designing agricultural transformation strategies that modernize small-scale farming in Africa require actions built upon solid, holistic baselines and proven, affordable technical intervention. A study was conducted in west Kenya to characterize the farming operations and household condition among smallhold farmers. The assessment consisted of a structured survey among 291 randomly selected households and compiled onto a single spreadsheet with rows as household cases and 98 descriptors as columns. Overall summary statistics were calculated, and then stratified by three criteria; household resource endowment, agro-ecological zone and sex of household head. A farming systems diagram was inferred from these results. Overall average farm size is 0.87 ha, family size is 6.8 persons and majorities of those interviewed were household heads (68\% of respondents) and women $(58 \%$ of respondents). A simple parameter of resource endowment describes weighted per capita field area per household member of about $1800 \mathrm{~m}^{2}$. Household income is $\$ 466$ per year, food shortfalls last 110 days per year, and households produce $819 \mathrm{~kg}$ cereals, $211 \mathrm{~kg}$ grain legumes and $74 \mathrm{~kg}$ root crops per year. These households raised 2.5 cattle, 1.4 goats or sheep and 13 chickens, deriving annual incomes of $\$ 78$ from animal enterprise. The $39 \%$ of households with lowest resource endowment $\left(<1000 \mathrm{~m}^{2}\right.$ per capita) operate on only 0.34 ha per farm, earn only $\$ 155$ per year, suffer food shortfalls of 122 days per year, and households produce $326 \mathrm{~kg}$ cereals and $119 \mathrm{~kg}$ grain legumes. Of the three agro-ecological zones within the study area, the Midlands offers the greatest opportunity for interventions as the Lake Victoria Basin is drier and the Upper Midlands is becoming peri-urban. Large contrasts were observed between womenand men-led households, with the former on farms 0.4 ha smaller, annual income $\$ 168$ less, 18 additional days of hunger per year and producing $248 \mathrm{~kg}$ less cereals and $94 \mathrm{~kg}$ less grain legumes. Organic resource availability was approximately 3.3 tons per year and allocated in a variety of ways, with women allocating three-fold more manure to grain legumes, and most palatable crop residues being passed through livestock. These findings compare favorably
\end{abstract}

to the four key entry points independently identified by the Humidtropics Program for its West Kenya Action Site; Legume Integration, Striga Elimination, Crop Diversity and Animal Enterprise, and interactions between these entry points offer promising lines to farming systems research in the future.

Keywords East Africa, Farming Systems, Gender Equity, Humidtropics Program, Maize-based Agriculture, Resource Endowment, Smallholder Farming

\section{Introduction}

Farming operations throughout the humid tropics are complex, diverse and dynamic. The Humidtropics Program [1] seeks to better understand the status of farming system activities including the roles of natural resource endowment and gender, and to identify robust approaches to their improvement. In this way, a more detailed understanding of farm practices and livelihood strategies allows better informed priority setting of individual farm enterprises and overall systems performance. These understandings also form the baseline for later improvement of farm productivity and household enterprise, and allow better linkage to rural development plans of national and local institutions.

Technical solutions are available for many constraints faced by small-scale African farmers, but it is their cost and delivery that poses challenges. Systems analysis and synthesis serves to identify the most promising interventions through balanced priority setting for increased production, poverty alleviation, market development, natural resource integrity, and biodiversity enhancement. It is intended to provide a baseline from which to assess the impacts of various research trajectories and eventually contribute to a larger developmental synthesis. An integrated systems approach also includes a strong component of site specificity, an element driven by key research questions [1]. Three of these questions are considered for the small-scale farming 
systems of west Kenya: 1) What are the predominant farm enterprises and management practices and how do these vary among different categories of stakeholder, 2) What are the current production systems challenges and opportunities to enhance productivity and natural resource integrity and 3) What is the current status of vulnerable groups including women, in rural economies and what opportunities exist to improve their equity and wellbeing by increasing systems diversity and productivity?

Our approach is based upon the assumption that on-farm problem solving is best directed toward individual farm enterprises that are stratified among different categories of stakeholder. Both established and emerging technologies have the potential to increase production and returns [2] and the farm may be viewed as an aggregate of those enterprises assembled by their land managers. An impact assessment was conducted in west Kenya by the N2Africa Program [2] that was primarily intended to quantify early gains among farm communities and stakeholders from outreach efforts in terms of legume enterprise and BNF technology adoption. But the approach also collected a wider range of information about households and farming practice that provides insight into farm household wellbeing and their agricultural enterprises and management, and the following analysis is based upon that wealth of information.

\section{Materials and Methods}

The assessment of small-scale farmers in west Kenya consisted of a structured household survey divided into six parts. General information described household members, their education, farm animals and sources of income. Inputs covered their use in different farm enterprises and training in their application. Land holding covered farm size, field areas and current crop management. Crop production and use queried on the past year's yield of the different enterprises and proportions used by the household, sold or saved as seed. Changes in land use asked that managers comment on trends in crop selection over the past four years (over the course of the N2Africa Project) and reasons for those shifts. Household nutrition examined which foods are consumed, how they are prepared and how food availability changes during the year. Each survey interview required about 40 minutes to one hour and was conducted during the dry season between the 2012-2013 short rains (ending in early January) and 2013 long rains (starting in April). Eight enumerators were trained in use of the survey instrument and 291 household interviews conducted during February and March 2013. Note that "west Kenya" consists of the former Western Province administrative area disbanded following constitutional reform and that 300 households were targeted for survey but some proved inaccessible due to intense aseasonal rainfall.

Households were selected at random from a database of farmers working with the N2Africa Project [2] during 2010 and 2011. Results from each household were compiled into a single spreadsheet file with different sections appearing as worksheets, then later combined into a single spreadsheet with 291 rows as cases and 98 descriptors as columns. After inspection for errors and sorting, summary statistics were performed on these data. Households were stratified by agro-ecological zone (AEZ), resource endowment (land per household member) and gender. The three AEZs; Lake Victoria Basin, Midlands and Upper Midlands, correspond to elevations $<1300 \mathrm{~m}, 1300$ to $1500 \mathrm{~m}$ and $>1500 \mathrm{~m}$. respectively [3]. Resource endowment is based upon farm area and household size, and considers children younger than 16 to be 0.5 adults. Gender analysis is based upon responses by head of households only, divided between men and women. A gender equity index was developed where quantitative characteristics in women's and men's households were compared and a $20 \%$ difference employed as an interpretive threshold.

\section{Results}

Table 1. Key characteristics among small-scale households in the west Kenya Action Site $(\mathrm{n}=291, \pm$ Standard Deviation).'

\begin{tabular}{|ccc|}
\hline Characteristic & mean or frequency $(f)$ \\
\hline Elevation (masl) & 1408 & \pm 147 \\
Farm size (ha) & 0.87 & \pm 0.91 \\
Women interviewed $(f)$ & 0.58 & \\
Age of interviewee (yr) & 47 & \pm 13 \\
Interviewee household head (f) & 0.68 & \\
Household size (n) & 6.8 & \pm 2.6 \\
Resource endowment (ha per capita) & 0.18 & \pm 0.18 \\
\hline
\end{tabular}

Table 2. Farm activities among small-scale households in the west Kenya Action Site $(\mathrm{n}=291)$.

\begin{tabular}{|cc|}
\hline Farm activity & $f$ \\
\hline Cultivate maize & 0.99 \\
Intercrop maize & 0.79 \\
Cultivate beans & 0.75 \\
Market legumes & 0.46 \\
Cultivate other cereals & 0.32 \\
Cultivate groundnuts & 0.22 \\
Cultivate potatoes & 0.16 \\
Cultivate minor legumes & 0.14 \\
Cultivate cassava & 0.12 \\
Grow cash crops & 0.10 \\
\hline
\end{tabular}

Table 3. Farm practices among small-scale households in the west Kenya Action Site $(\mathrm{n}=291)$.

\begin{tabular}{|cc|}
\hline Farm practice & $f$ \\
\hline Transfer legume residues & 0.81 \\
Feed legume residues & 0.56 \\
Make compost/store manure & 0.54 \\
Apply NP fertilizer & 0.49 \\
Practice fallowing & 0.38 \\
Purchase fertilizer locally & 0.35 \\
Topdress with N fertilizer & 0.13 \\
Practice mulching & 0.11 \\
Transfer fresh manure/urine & 0.11 \\
\hline
\end{tabular}

A detailed household survey was conducted among 291 small-scale farming households in west Kenya that included 
sufficient information to develop a farming systems model for different agro-ecological and socio-economic strata. Overall household characteristics appear in Table 1 and we note that average farm size is rather small (0.87 ha), interviewees were older (average 47 years old) and a majority were either the intended head of household $(68 \%$ of respondents) and/or women (58\% of respondents). Resource endowment based upon per capita field area per household member was about $1800 \mathrm{~m}^{2}$. Table 2 describes farm activities with maize and bean intercropping predominant, although other cereals and legumes are common. Less importance is placed upon root and cash crops within these farms. Farm management practices are described in Table 3 with crop residues frequently being transferred between fields, fed to livestock and used in composting. Many households apply pre-plant nitrogen- and phosphorous-bearing mineral fertilizers (49\%), most of which is purchased from local agrodealers (71\%). Least common practices include top-dressing with mineral $\mathrm{N}$, mulching or transfer of fresh manure and urine, all managements with proven efficacy. Compiled data were organized into a farming system diagram that depicts crop and animal enterprises, resource transfers, household food supply and income (Figure 1). This approach suggests that income from sales of cereals, legumes and animals constitute $76 \%$ of the household income of $\$ 466$ per year, and that food or nutritional shortfalls are experienced during 110 days per year. Some elements of this model are based upon outside information (e.g. commodity prices) and assumptions (crop residues as 1 - Harvest Index) and some resource flows are absent for lack of information (e.g. livestock feed from root and cash crops).

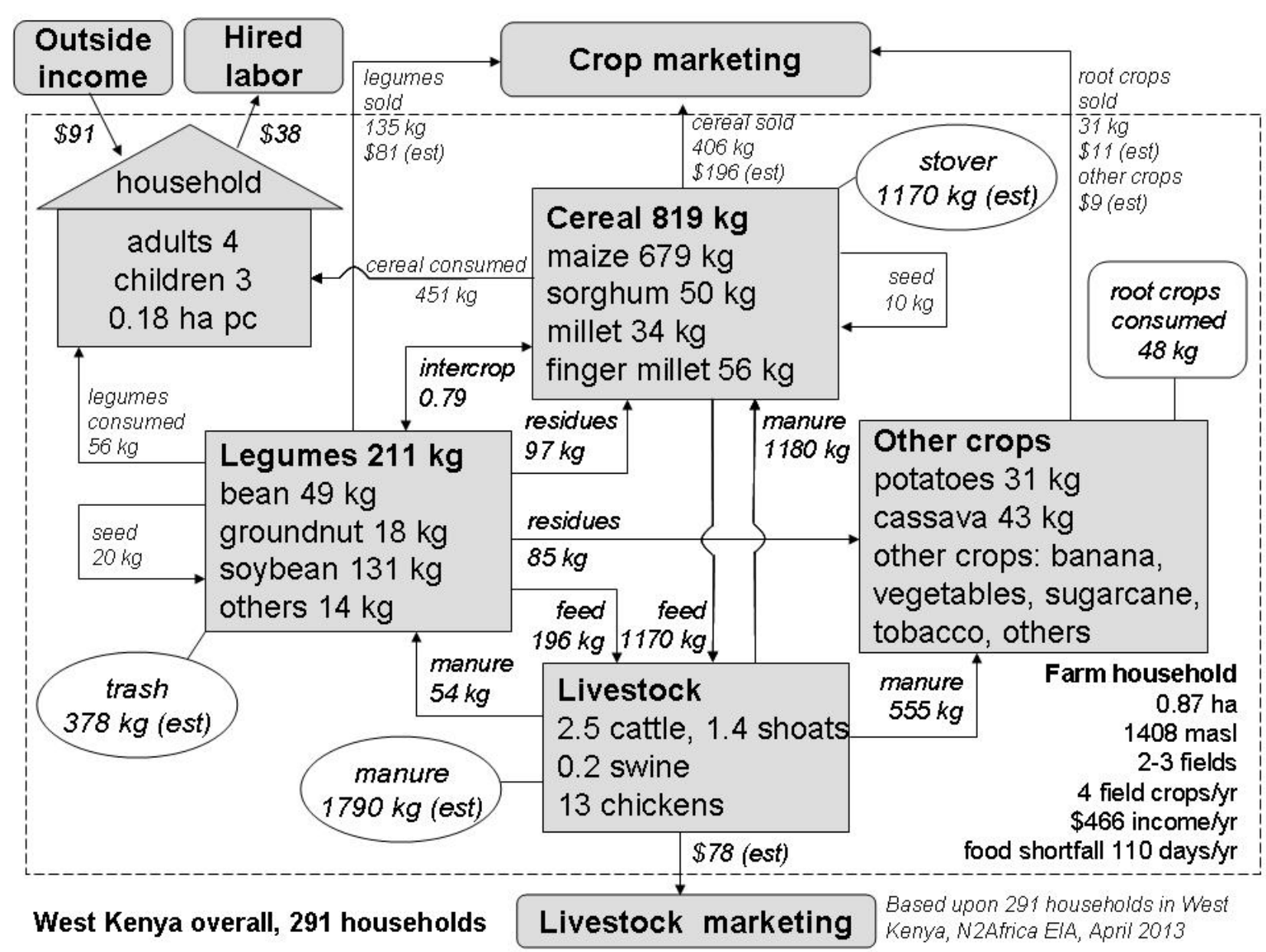

Figure 1. A farming systems diagram depicting crop yields, farm animals, food supply, resource transfers and livelihood among small-scale farmers in the West Kenya Action Site based upon a household survey conducted by the N2Africa Project in 2013. 
These households were also examined from the perspective of resource endowment based upon per capita land availability. More households fall into the Low Endowment category ( $39 \%$ of households with $<0.1$ ha per member) and fewest in the highest category $(29 \%$ of households with $>0.2$ ha per member). Highest Resource Endowments are associated with lower elevations, larger farms, smaller households, greater incomes from farming and a $53 \%$ increase in farm hired labor versus working outside the farm (Table 4). All endowment categories rely primarily upon maize-legume intercropping but large differences exist between maize and legume harvests and marketing (Table 5). Less differences occur within animal enterprises although poorer households tend to own slightly fewer cattle, sheep, goats and poultry (Table 6). A farming system diagram of the least endowed households (Figure 2) suggests much lower food supply, and farm income compared to the overall household (Figure 1) and the two other resource endowment categories (data not presented). The least resource endowed households rely more upon intercropping and have fewer organic resources at their disposal. In many cases, the need to market a larger proportion of their smaller harvests predisposes these households to longer duration shortfalls of food supply $(+27$ days, data not presented), and their hunger season, when no food available from the farm, is of longer duration $(+15$ days per year, data not presented) compared to higher resource endowments. Considering adults only, the per capita daily income of the least endowed households is only US $\$ 0.10$ per day, compared to $\$ 0.51$ for the highest endowment category, indicating inequity between households but also that all categories are considered impoverished using the international standard of US $\$ 1$ per day.

Table 4. Farm characteristics of different household resource endowment levels in west Kenya ${ }^{1}$.

\begin{tabular}{|c|c|c|c|c|c|c|}
\hline \multirow[t]{2}{*}{ Farm Characteristic } & \multicolumn{6}{|c|}{ Household Resource Endowment ( \pm SD) } \\
\hline & \multicolumn{2}{|c|}{ Low } & \multicolumn{2}{|c|}{ Modest } & \multicolumn{2}{|c|}{ Higher } \\
\hline frequency $(f)$ & \multicolumn{2}{|c|}{0.39} & \multicolumn{2}{|c|}{0.32} & \multicolumn{2}{|c|}{0.29} \\
\hline farm elevation (masl) & 1448 & \pm 159 & 1384 & \pm 142 & 1384 & \pm 121 \\
\hline farm size (ha) & 0.34 & \pm 0.17 & 0.75 & \pm 0.36 & 1.73 & \pm 1.25 \\
\hline Household members (no) & 7.5 & \pm 2.5 & 6.7 & \pm 2.4 & 5.8 & \pm 2.7 \\
\hline Hectare per capita (ha/person) & 0.06 & \pm 0.02 & 0.14 & \pm 0.03 & 0.39 & \pm 0.21 \\
\hline Income derived from crops (\%) & 60 & \pm 22 & 61 & \pm 25 & 69 & \pm 24 \\
\hline Work outside of farm (\%) & 50 & \pm 50 & 39 & \pm 49 & 31 & \pm 47 \\
\hline Hire others to work on farm (\%) & 65 & \pm 48 & 78 & \pm 41 & 84 & \pm 37 \\
\hline
\end{tabular}

${ }^{1}$ Based on adjusted hectare per capita where resource endowment $=$ farm size $($ ha $) /($ household adults +0.5 household children), $<0.1$ is poor $(\mathrm{n}=113$ ), 0.1 to 0.2 is modest $(n=93)$ and $>0.2$ is high $(n=83)$.

Table 5. Animal ownership by households belonging to different resource endowment categories in west Kenya ${ }^{1}$.

\begin{tabular}{|c|c|c|c|c|c|c|}
\hline \multirow{3}{*}{$\begin{array}{c}\text { Animal } \\
\text { Ownership } \\
\text { Cattle (n) }\end{array}$} & \multicolumn{6}{|c|}{ Household Resource Endowment ( \pm SD) } \\
\hline & \multicolumn{2}{|c|}{ Low } & \multicolumn{2}{|c|}{ Modest } & \multicolumn{2}{|c|}{ Higher } \\
\hline & 2.0 & \pm 1.7 & 2.8 & \pm 2.8 & 2.9 & \pm 2.5 \\
\hline Sheep and goats (n) & 1.0 & \pm 1.5 & 1.6 & \pm 2.6 & 1.9 & \pm 2.3 \\
\hline Swine (n) & 0.2 & \pm 0.7 & 0.1 & \pm 0.5 & 0.1 & \pm 0.4 \\
\hline Poultry (n) & 10 & \pm 11 & 17 & \pm 46 & 14 & \pm 18 \\
\hline
\end{tabular}

${ }^{1}$ Based on adjusted hectare per capita where resource endowment $=$ farm size (ha) $/($ household adults +0.5 household children), $<0.1$ is poor $(\mathrm{n}=104), 0.1$ to 0.2 is modest $(n=90)$ and $>0.2$ is high $(n=76)$.

Table 6. Cropping characteristics at different resource endowment levels ${ }^{1}$ in west Kenya.

\begin{tabular}{|c|c|c|c|c|c|c|}
\hline \multirow{3}{*}{$\begin{array}{c}\text { Farm Characteristic } \\
\text { Intercrop cereals and legumes }(\%)\end{array}$} & \multicolumn{6}{|c|}{ Household Resource Endowment ( \pm SD) } \\
\hline & \multicolumn{2}{|c|}{ Low } & \multicolumn{2}{|c|}{ Modest } & \multicolumn{2}{|c|}{ Higher } \\
\hline & 86 & \pm 34 & 73 & \pm 45 & 78 & \pm 42 \\
\hline Cultivate maize $(\%)$ & 99 & & 100 & & 99 & \\
\hline Annual maize harvest (kg) & 355 & \pm 439 & 617 & \pm 1073 & 1200 & \pm 2030 \\
\hline Markets maize (\% of households) & 14 & \pm 24 & 24 & \pm 27 & 38 & \pm 30 \\
\hline Cultivate beans $(\%)$ & 83 & \pm 38 & 67 & \pm 47 & 74 & \pm 44 \\
\hline Annual bean harvest (kg) & 40 & \pm 38 & 71 & \pm 57 & 141 & \pm 161 \\
\hline Markets legumes (\% of households) & 40 & \pm 33 & 47 & \pm 29 & 53 & \pm 31 \\
\hline
\end{tabular}

${ }^{1}$ Based on adjusted hectare per capita where resource endowment $=$ farm size (ha)/(household adults +0.5 household children), $<0.1$ is poor ( $\left.\mathrm{n}=110\right), 0.1$ to 0.2 is modest $(n=91)$ and $>0.2$ is high $(n=82)$. 


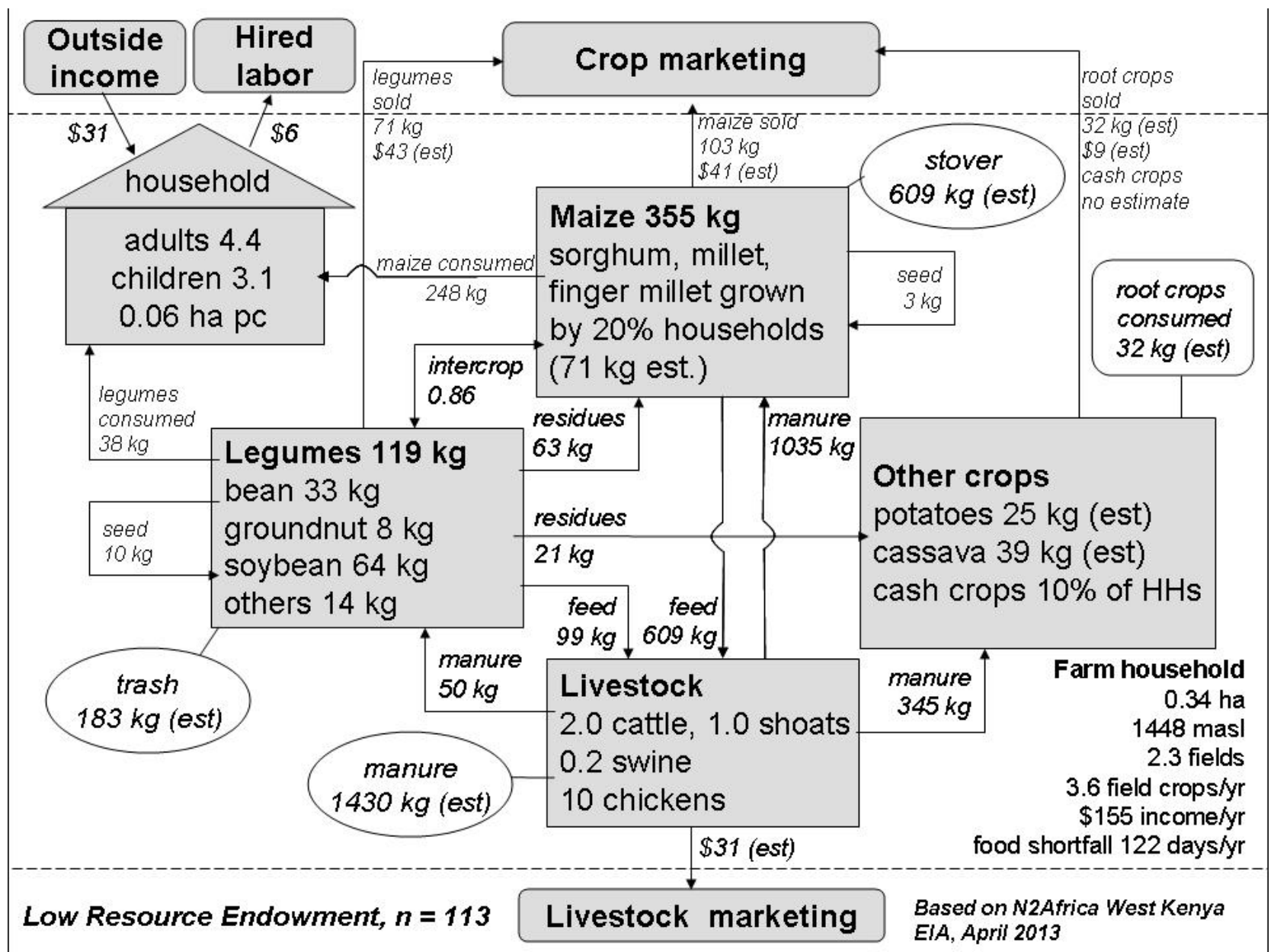

Figure 2. Livelihood and farm characteristics of households assigned low resource endowments in the West Kenya Action Site (based upon $<0.1$ ha per capita with children $<16$ years of age assigned weight of 0.5 ).

Table 7. Farm characteristics in three adjacent agro-ecological zones in west Kenya $( \pm \mathrm{SD})^{1}$.

\begin{tabular}{|c|c|c|c|c|c|c|}
\hline \multirow{2}{*}{ Farm Characteristic } & \multicolumn{6}{|c|}{ Agro-ecological Zone $( \pm \mathrm{SD})$} \\
\hline & \multicolumn{2}{|c|}{ Lake Basin } & \multicolumn{2}{|c|}{ Midland } & \multicolumn{2}{|c|}{ Upper Midland } \\
\hline frequency $(f)$ & \multicolumn{2}{|c|}{0.28} & \multicolumn{2}{|c|}{0.39} & \multicolumn{2}{|c|}{0.33} \\
\hline farm elevation (masl) & 1223 & \pm 51 & 1392 & \pm 67 & 1579 & \pm 44 \\
\hline farm size (ha) & 0.77 & \pm 0.78 & 1.07 & \pm 0.94 & 0.61 & \pm 0.55 \\
\hline Household members (no) & 6.4 & \pm 2.4 & 6.9 & \pm 2.8 & 6.9 & \pm 2.4 \\
\hline Hectare per capita (ha/person) & 0.16 & \pm 0.16 & 0.23 & \pm 0.21 & 0.12 & \pm 0.11 \\
\hline Income derived from farm (\%) & 81 & \pm 22 & 85 & \pm 20 & 78 & \pm 22 \\
\hline Work outside of farm (\%) & 49 & \pm 50 & 40 & \pm 49 & 35 & \pm 48 \\
\hline Hire others to work on farm (\%) & 72 & \pm 45 & 79 & \pm 41 & 71 & \pm 45 \\
\hline
\end{tabular}

${ }^{1}$ Based upon elevation (masl) where $<1300=$ Lake Victoria Basin $(\mathrm{n}=79), 1300-1500=$ Midlands $(\mathrm{n}=108)$ and,$>1500=$ Upper Midlands $(\mathrm{n}=91)$.

These households were also separated by elevation in intervals of $200 \mathrm{~m}$, representing three different agro-ecological zones and resulting in useful contrasts between the Lake Victoria Basin, the Midlands and the Upper Midlands. These three zones have semi-humid, sub-humid and humid climates, respectively, and range from warm to mild. This elevational transect starts at the shores of Lake Victoria and ends before the West Kenya Highlands, a cool zone characterized by forests, large commercial farms and tea plantations [3]. More and larger farms appear in the Midlands, an area characterized by reliable bimodal rains and red Ferralsols (Table 7). The Upper Midlands has large areas of peri-urban settlement where a wide variety of crops may be cultivated including those associated with temperate regions (e.g. coles, Irish potatoes, carrots). Originally, these two zones represented the furthest eastward expansion of the Guinean-Congolian Humid Forest that is now mostly cleared for agriculture. The Lake Basin is much drier, originally 
moist savanna but now intensively cultivated and grazed.

Despite differences in climate, all of these zones are committed to maize-based farming (Table 8) and intercropping with legumes, mostly common bean but also groundnut, cowpea, green gram and more recently soybean. Farm yields of maize and beans remain low, particularly due to widespread striga in the former case and disease in the latter, although tolerant varieties and control technologies have become increasingly available. West Kenya is considered to be a food deficit area and local prices for beans are the highest in Kenya throughout the year. Ownership of cattle, goats and sheep reflect farm size, but poultry and swine are more abundant at lower elevations (Table 9). Farming system diagrams similar to Figures 1 and 2 were prepared for each of these three zones but not included in this report. Annual incomes range between $\$ 187$ in the Lake Basin to $\$ 396$ in the Midlands. Food shortfalls are greatest in the Upper Midlands (128 days per year), partly due to a greater frequency of small-scale cash cropping at the expense of staple food crops. Another distinguishing feature of the Lake Basin is that cassava and cereal crops other than maize are much more frequently cultivated and consumed by households.

These data were also stratified by women versus men as head of household. First, $32 \%$ of the cases where those interviewed were not heads were discarded and then 117 male- and 79 female-headed households compared in terms of farm characteristics, cropping and management. These contrasts were assisted through the development of an equity index that directly quantifies these differences and a threshold of $20 \%$ used to indicate strong divergence between farms. In this way, women-headed farms and households are $40 \%$ smaller, and operate under a $28 \%$ reduced resource endowment and $29 \%$ less opportunity for off-farm income (Table 10). These women-headed households have a $62 \%$ extended hunger season but, interestingly $28 \%$ greater access to local markets. Harvests of both maize and legumes are about 38\% less in women-headed households, and cassava and cash crops are produced less frequently (Table 11). However, legume (2.8-fold) and minor cereal $(+34 \%)$ production are more important farm enterprises and there is 3 -fold greater commitment to controlling striga using imazapyr-resistant maize. Women-headed households practice fewer soil management technologies (e.g. N top-dressing and fallowing), and have fewer cattle $(-30 \%)$ and poultry $(-38 \%)$, but much more of their manure is applied to legumes (Table 12).

A farming system diagram that contrasts the characteristics of women-headed households further illustrates the inequities among households (Figure 3). Maize and legume yields are 33\% lower and less organic resources are derived and transferred between them, except for women's $+88 \%$ special attention to manuring legumes. Incomes are lower both from crops and livestock farming $(-59 \%)$ and off-farm sources $(-51 \%)$. It is revealing that women-headed farms harvest $30 \%$ less beans, and consume and market $34 \%$ and $40 \%$ less beans respectively, but retain a similar amount for planting the following season $(\sim 13 \mathrm{~kg}$ per season). Despite $34 \%$ greater frequency of cultivating minor cereals (Table 11), less harvests are obtained from them as well. There is an indication that women's farming operations are more diverse as their smaller farms contain more, smaller fields that support a greater number of enterprises. When comparing male- and female-headed households, it is important that the former most likely has at least one woman household member, while the latter lacks a man with sufficient farming experience to serve as head. For example, fewer female-headed households process legumes into value added products, presumably because women in male-headed households have greater resources and time to do so.

Table 8. Cropping characteristics in different agro-ecological zones in west Kenya ${ }^{1}$.

\begin{tabular}{|c|c|c|c|c|c|c|}
\hline \multirow{3}{*}{$\begin{array}{c}\text { Farm Characteristic } \\
\text { Intercrop cereals and legumes }(\%)\end{array}$} & \multicolumn{6}{|c|}{ Agro-ecological Zone $( \pm \mathrm{SD})$} \\
\hline & \multicolumn{2}{|c|}{ Lake Basin } & \multicolumn{2}{|c|}{ Midland } & \multicolumn{2}{|c|}{ Upper Midland } \\
\hline & 77 & \pm 43 & 81 & \pm 40 & 79 & \pm 41 \\
\hline Cultivate maize $(\%)$ & 100 & & 99 & & 99 & \\
\hline Annual maize harvest (kg) & 371 & \pm 419 & 925 & \pm 1619 & 595 & \pm 1276 \\
\hline Markets maize (\% of households) & 19 & \pm 22 & 30 & \pm 30 & 20 & \pm 29 \\
\hline Cultivate beans (\%) & 62 & \pm 49 & 78 & \pm 42 & 83 & \pm 38 \\
\hline Annual bean harvest $(\mathrm{kg})$ & 71 & \pm 102 & 123 & \pm 149 & 27 & \pm 17 \\
\hline Markets legumes (\% of households) & 46 & \pm 28 & 50 & \pm 30 & 40 & \pm 36 \\
\hline
\end{tabular}

${ }^{1}$ Based upon elevation (masl) where $<1300=$ Lake Victoria Basin $(n=77), 1300-1500=$ Midlands $(n=108)$ and , $>1500=$ Upper Midlands $(n=87)$.

Table 9. Animal ownership by households in different agro-ecological zones in west Kenya ${ }^{1}$.

\begin{tabular}{|cccccccc|}
\hline Animal ownership & \multicolumn{2}{c}{ Lake Basin } & \multicolumn{2}{c|}{ Agro-ecological Zone ( \pm SD) } \\
& \multicolumn{2}{c}{ Midland } & \multicolumn{2}{c|}{ Upper Midland } \\
\hline Cattle (n) & 2.5 & \pm 2.4 & 2.8 & \pm 2.7 & 2.2 & \pm 1.8 \\
Sheep and goats (n) & 1.3 & \pm 1.8 & 1.8 & \pm 2.8 & 1.1 & \pm 1.5 \\
Swine (n) & 0.3 & \pm 0.7 & 0.2 & \pm 0.6 & 0 & \\
Poultry (n) & 20 & \pm 50 & 13 & \pm 16 & 8 & \pm 15 \\
\hline
\end{tabular}

${ }^{1}$ Based upon elevation $($ masl) where $<1300=$ Lake Victoria Basin $(n=73), 1300-1500=$ Midlands $(n=103)$ and,$>1500=$ Upper Midlands $(n=85)$. 
Table 10. Selected characteristics among male- and female- headed households in the West Kenya Action Site ( \pm Standard Deviation).

\begin{tabular}{|cccccccc|}
\hline Farm characteristic & \multicolumn{3}{c}{ Head of Household } & Equity & Comment \\
& \multicolumn{2}{c}{ Male $^{1}$} & Female & Index & \\
\hline Farm elevation (masl) & 1410 & \pm 152 & 1407 & \pm 152 & 1.00 & both operate across identical AEZs \\
Farm size (ha) & 1.0 & \pm 1.0 & 0.6 & \pm 0.4 & 0.60 & women operate smaller farms \\
Age of head (yr) & 49 & \pm 14 & 48 & 10 & 0.98 & household heads are same age range \\
$\begin{array}{c}\text { Household members (n) } \\
\text { Resource endowment (ha per } \\
\text { capita) }\end{array}$ & 7 & \pm .21 & \pm 0.20 & 0.15 & \pm 0.14 & 0.72 & women head slightly smaller households \\
Off-farm income (frequency) & 0.14 & \pm 0.22 & 0.10 & \pm 0.16 & 0.71 & women's farms earn less off-farm income \\
$\begin{array}{c}\text { Market access (frequency) } \\
\text { Household hunger (yr) }\end{array}$ & 0.22 & \pm 0.29 & 0.29 & \pm 0.28 & 1.28 & women's farms enjoy more local market access \\
\hline
\end{tabular}

${ }^{1}$ Based upon interviews of 117 male-headed households (MHH). ${ }^{2}$ Based upon interviews of 79 female-headed households (FHH). ${ }^{3}$ Equity Index $=$ FHH/MHH.

Table 11. Selected cropping characteristics among male- and female- headed households in the West Kenya Action Site ( \pm Standard Deviation).

\begin{tabular}{|c|c|c|c|c|c|c|}
\hline \multirow{3}{*}{$\begin{array}{c}\text { Farm characteristic } \\
\text { Annual maize harvest (kg) }\end{array}$} & \multicolumn{4}{|c|}{ Head of Household } & \multirow{3}{*}{$\begin{array}{c}\text { Equity } \\
\text { Index }^{3} \\
0.67\end{array}$} & \multirow{3}{*}{$\begin{array}{c}\text { Comment } \\
\text { women heads harvest } 33 \% \text { less maize }\end{array}$} \\
\hline & \multicolumn{2}{|c|}{ Male $^{1}$} & \multicolumn{2}{|c|}{ Female $^{2}$} & & \\
\hline & 704 & \pm 1330 & 473 & \pm 623 & & \\
\hline Plant IR-resistant maize & 3 & \pm 16 & 8 & \pm 27 & 3.08 & women more actively combat striga \\
\hline Cultivate other cereals & 0.26 & \pm 0.44 & 0.35 & \pm 0.48 & 1.34 & includes sorghum, millet, finger millet \\
\hline Annual legume harvest $(\mathrm{kg})$ & 217 & \pm 256 & 149 & \pm 318 & 0.69 & women heads harvest $31 \%$ less grain legumes \\
\hline Cultivate beans $(\%)$ & 63 & \pm 48 & 81 & \pm 39 & 1.28 & women heads grow beans $28 \%$ more often \\
\hline Cultivate minor legumes (\%) & 6 & \pm 47 & 24 & \pm 79 & 3.84 & includes green gram, bambara nut, cowpea \\
\hline Cultivate cassava (\%) & 14 & \pm 35 & 8 & \pm 27 & 0.57 & women heads cultivate less cassava \\
\hline Cultivate cash crops (\%) & 13 & \pm 33 & 9 & \pm 29 & 0.75 & includes sugarcane, tobacco, others \\
\hline
\end{tabular}

${ }^{1}$ Based upon interviews of 117 male-headed households (MHH). ${ }^{2}$ Based upon interviews of 79 female-headed households (FHH). ${ }^{3}$ Equity Index $=$ $\mathrm{FHH} / \mathrm{MHH}$.

Table 12. Selected farm management characteristics among male- and female- headed households in the West Kenya Action Site ( \pm Standard Deviation).

\begin{tabular}{|c|c|c|c|c|c|c|}
\hline \multirow{3}{*}{$\begin{array}{c}\text { Farm characteristic } \\
\text { Top dress w/mineral } \mathrm{N}(f)\end{array}$} & \multicolumn{4}{|c|}{ Head of Household } & \multirow{3}{*}{$\begin{array}{c}\text { Equity } \\
\text { Index }^{3} \\
0.68\end{array}$} & \multirow{3}{*}{$\begin{array}{c}\text { Comment } \\
\text { women heads top dress } \mathrm{w} / \mathrm{N} \text { maize less often }\end{array}$} \\
\hline & \multicolumn{2}{|c|}{ Male $^{1}$} & \multicolumn{2}{|c|}{ Female $^{2}$} & & \\
\hline & 0.16 & \pm 0.36 & 0.11 & \pm 0.31 & & \\
\hline Practice land fallow $(f)$ & 0.44 & \pm 0.50 & 0.35 & \pm 0.48 & 0.80 & women heads practice fallow less often \\
\hline Fallow interval (yr) & 1.7 & \pm 1.7 & 1.1 & \pm 0.5 & 0.64 & fallow intervals are shorter on women's farms \\
\hline Raise cattle (n) & 2.7 & \pm 2.4 & 1.9 & \pm 1.7 & 0.70 & women own $30 \%$ less cattle \\
\hline Raise poultry (n) & 17.5 & \pm 42.5 & 10.8 & \pm 17.6 & 0.62 & women own $29 \%$ less poultry \\
\hline Apply manure to legumes $(f)$ & 0.03 & \pm 0.16 & 0.08 & \pm 0.27 & 3.08 & women manure legumes more often \\
\hline
\end{tabular}

${ }^{1}$ Based upon interviews of 117 male-headed households (MHH). ${ }^{2}$ Based upon interviews of 79 female-headed households $(\mathrm{FHH}) .{ }^{3}$ Equity Index $=$ FHH/MHH. 


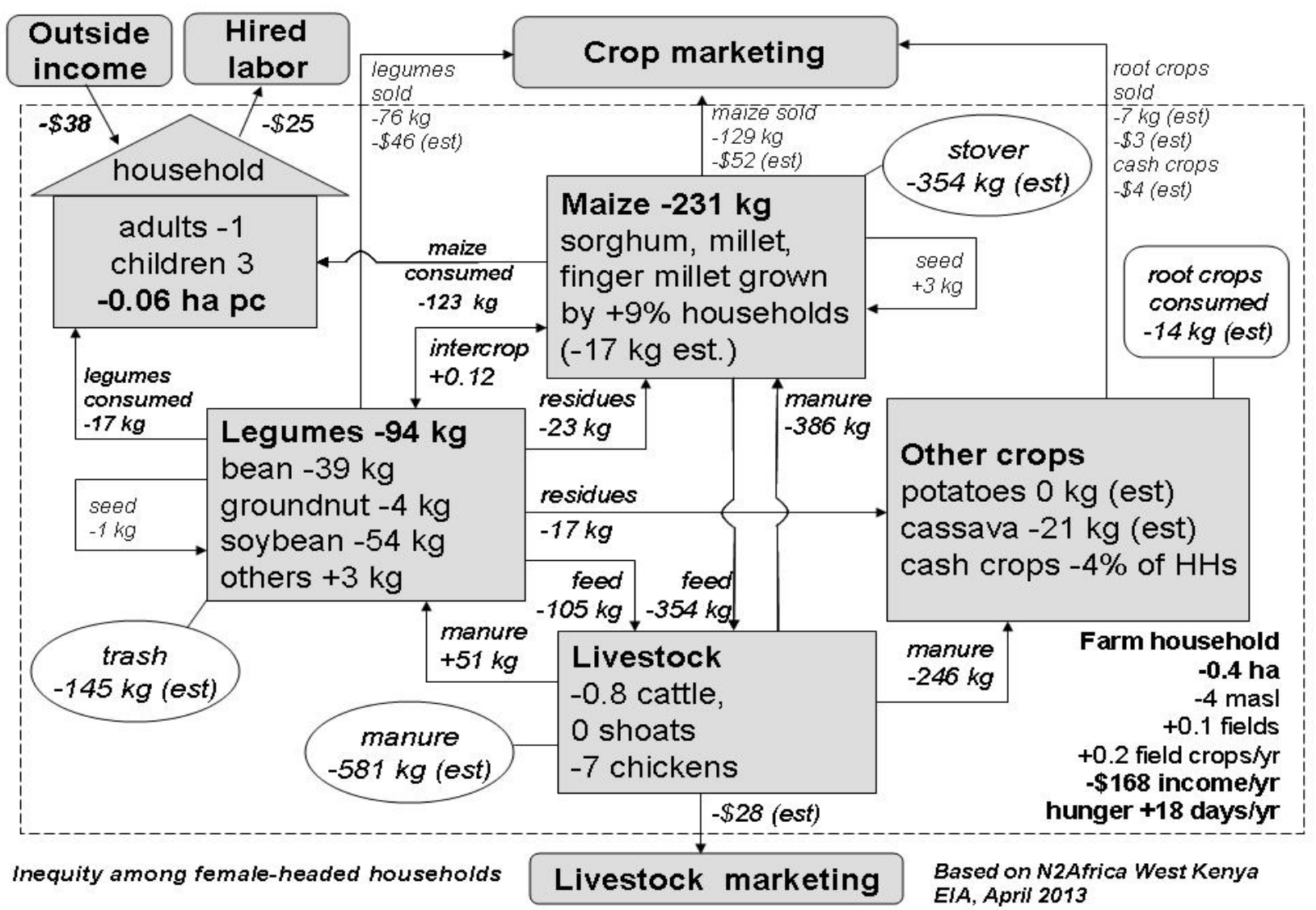

Figure 3. Farm and household characteristics of female-headed households compared to male-headed ones in the West Kenya Action Site.

\section{Discussion}

An overall picture of small-scale farming households and systems may be cast. These farmers operate compact farms largely committed to maize-based intercropping that also includes other crop and animal enterprises [4]. Even the households with greater resource endowments are impoverished by current developmental standards, and the poorest households face food and nutritional insecurity. Most income is derived from the farm but many households obtain some income from off-farm employment and remittance. While an overall understanding of rural households within west Kenya is useful, stratifying these households by resource endowment, agro-ecological zone and household leadership is particularly revealing.

Our classification of resource endowment based only upon weighted per capita land availability is somewhat simplistic compared to other efforts [4], but simple differences between household categories proves revealing. Households operating farms with less than 0.1 ha per family member face many constraints in terms of food supply and income, but are also in a position to intensify farming operations and engage in value added activities not available to larger farms and smaller families. While this advantage is consistent with Humidtropics [1] philosophy toward improving livelihoods, it is often the result of increased population to the point of peri-urbanization where the future of farming itself is in jeopardy [5]. Furthermore, it is likely that different interventions are relevant within resource endowment categories, so for a fuller range of proven management options to reach their targets, a more complete suite of resource endowments need be considered [6,7]. Just income status alone suggests that some households are much better positioned to invest in farm inputs while others must direct a greater proportion of labor toward more efficient use of available organic resources.

Despite maize-based cropping being the predominant farming strategy across west Kenya, its separation into three different agro-ecologies is revealing. As these zones constitute an elevational transect and rainfall is greatest at its upper extreme; temperature, moisture availability and water use efficiency are confounded, resulting in different cropping opportunities [3]. The study area itself offers a wide range of agro-ecologies and socio-economic settings relevant elsewhere in Africa. The Lake Victoria Basin is semi-humid at best, originally consisted of woody savanna, experiences occasional drought and its soils are considerably less weathered than the other two zones [3]. The Midlands on the other hand was originally forest and has wider relevance to other upland areas in East Africa and beyond. Similarly, the Upper Midlands are quite similar to montane areas in west Uganda, Rwanda and eastern DR Congo and lessons learned may be applied to other densely populated settings across Africa. In this way, the study area in west Kenya 
contains three important agro-ecological zones in close proximity that permits contrasts between candidate interventions and easier understanding of site specificity.

A strength of this analysis is its gender differentiation. In part it is limited because many cases where non-heads were interviewed were discarded (Table 1) and superficial because it is stratified by the sex of household heads and male-headed households enjoy the efforts of women members but women-headed households often lack contributions from men. The survey does not distinguish between women-headed households where men are absent, working elsewhere and possibly providing remittances from those of widows and elderly. Nonetheless the contrasts between these differently-headed households are striking and disturbing. Women-headed households operate with fewer resources, on lower incomes and have less food, but with the same number of children, resulting in greater poverty. Despite these disadvantages, women-heads often direct their efforts in a more informed manner directed toward better diets [8, 9]. Observations concerning diet are however limited because the survey focused upon main farming enterprises and did not consider the importance of household kitchen gardens.

Any type of intervention that ignores gender issues may in fact increase vulnerability; hence, gender research and capacity building are integral to rural development and farming systems improvement [1]. While our approach to contrast men and women farmers' preferences for technologies based upon household leadership was fruitful, it does not consider the equally important dimension of intra-household decision making [8, 9]. Our approach does, however, demonstrate sufficient contrasts to identify opportunities for reducing gender inequalities, particularly at the farm level. In addition, this survey has established several indicators that provide evidence of gender inequalities and asset disparities for both male- and female-headed households as a means to capture gender differences (Tables 10, 11 and 12). Targeted inclusion of vulnerable groups in rural economies, including women, indigenous minorities, youth and elderly, provides insight into their equity, well-being, systems productivity and ecosystem integrity [1]. This study specifically includes women's farms and farming as a research focus and those working in west Kenya now have greater background information to move forward in this area.
It is important to note that the N2Africa Early Impact Assessment [2] that forms the core of this survey was conducted among farm households that participated in the dissemination of BNF technologies and improved varieties of two grain legumes, soybeans and climbing beans, for two or three years prior to survey. This participation included the distribution of small input packages intended for $200 \mathrm{~m}^{2}$ of recommended managements, training at the grassroots level, and access to technology demonstrations and farmer field days. Because N2Africa worked through community groups, all these farm households belong to a local farm association or work with a local NGO. The survey is thus skewed in terms of sample and intent, but nonetheless included a sufficient range of queries to allow for more holistic farming system interpretation. Thus the survey allows for the identification of key entry points. The initial survey itself was arguably under-analyzed as it was only utilized to establish the expansion of legume enterprise and adoption of BNF technologies across eight countries over four years in line with the N2Africa Vision of Success [2] and most of its data were never considered in subsequent reports and publications. This paper is intended to make these under-utilized findings from Kenya more widely available to the farming system and developmental research communities.

This situation analysis leads to a consideration of what sort of farming systems studies are likely to assist in fuller understanding of entry point interventions. Such interventions and their interactions may be arranged similar to the farming systems diagrams presented in the farming system analysis (Figure 4). This approach assumes that entry point $\mathrm{B}$ ) relating to striga and the recent invasion of Maize Lethal Necrosis Virus (MLNV) is principally responsible for reduced maize yields and that the main opportunities for $\mathrm{C}$ ) Crop Diversification relate primarily to root crops (cassava, potatoes and sweet potatoes). A) Legume Integration and B) Animal Enterprise readily cross-over between the two system approaches (e.g. comparing Figure 1 and Figure 4). Recommended approaches to measuring and monitoring these four key entry points are presented in Table 13. Most of these recommended parameters may be assessed from farm reconnaissance and a compact survey interview with any adult household member and may possibly be accommodated through more recent SMS queries. 


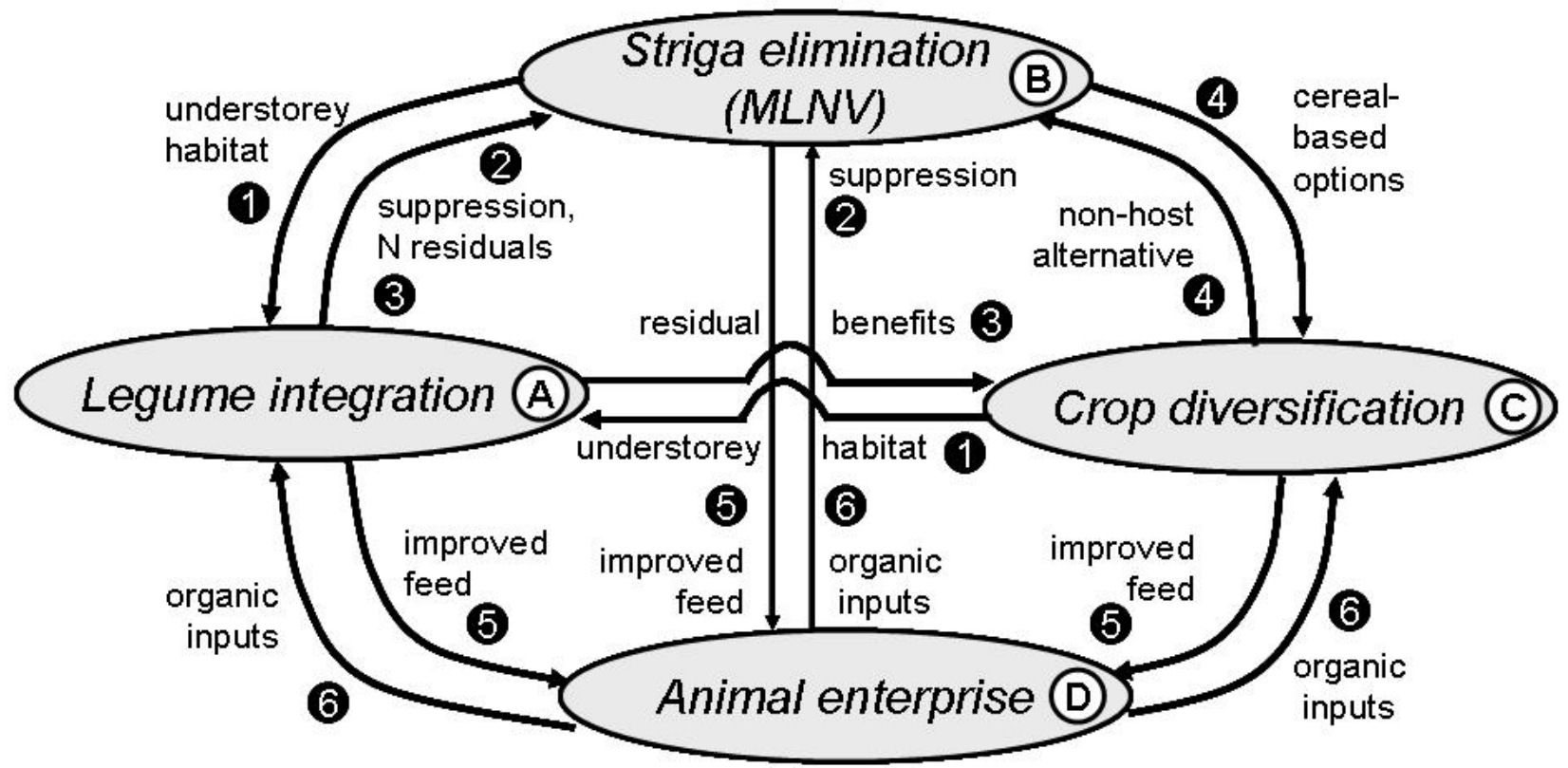

Figure 4. Key entry points for intervention and their possible resource transfers in small-scale farming systems by the Humidtropics Program in the West Kenya Action Site.

Table 13. Key entry points into the Humidtropics West Kenya Action Site, approaches to on farm measurement and underlying assumptions.

Legume Integration (A). Number of legume crops, use in rotation and intercropping, legume intensification index (\%) (= total field crops/(total legumes - bean)). Good baseline data from N2Africa Early Impact Assessment (EIA) and other secondary sources. Assumption: farmers moving from simple maize-bean intercropping to more complex and productive systems.

Striga Elimination (B). Striga infestation (y/n), striga intensity (= striga stems/maize stem), current farmer response, yield increase. Additional baseline data available from secondary sources. Assumption: striga is widespread in west Kenya and reduced in systems with greater crop diversity.

Crop Diversification (C). Number of field crops (= $\mathrm{n}$ over past two seasons). Assumption: more diverse cropping results from legume integration and striga control, root crop enterprise drives crop diversification in cereal legume systems.

Animal Enterprise (D). Numbers of cattle, $\Sigma$ goats \& sheep, swine, chickens, and rabbits (291 cases available from N2Africa (EIA). Assumption: Larger and more diverse livestock enterprise results from resource endowment and drives legume integration and crop diversification.

Table 14. Interactions between entry points in the West Kenya Action Site and opportunities for their on-farm assessment.

Understorey habit (1). Legume intercropping is driven by opportunities for understorey habitat (B1) particularly over-storey row width and understorey light penetration. Movement from over-storey to even-storey intercropping promotes legume integration (C1) as with dwarf cereals or shrubby legumes.

Striga suppression (2). Intercropping or rotation with selected legumes reduces striga infestation (A2). Application of fresh manure increases striga suppression (D2). Documentation requires measured changes in striga expression on maize (e.g. striga stems per plant) and the striga seed bank in soil between farms and over time.

Residual benefits from legumes (3). Legumes offer residual benefits to cereals and other field crops measured as both aboveground litter and below-ground root residues (A3).

Diversify cereal cropping (4). Farms with greater striga infestation are more inclined to diversify cereal cropping to less susceptible or non-host cereals (B3). This diversification in turn reduces striga infestation (C4).

Improved livestock feed (5). Legume integration (A5), striga reduction (B5) and crop diversification (C5) result in greater feed and better diets to farm animals. More diverse animal enterprise (D) allows for a wider range of crop residues to be used as feed (C5). Crop diversification includes establishment of fodder band when a critical number of livestock are reached (C5).

Manure and bedding use (6). Fresh manures are best applied to maize to suppress striga (B6). Other manures are best composted with bedding and other crop residues for use on higher value crops (D6). Well nodulated grain legumes receiving non-nitrogenous fertilizers do not require organic inputs from livestock enterprises (D6). Calculate manure availability based upon livestock ownership (D) and established rates of manure production head ${ }^{-1} \mathrm{y}^{-1}$. 
Less obvious and perhaps more important are the interactions between the four entry points, as indicated by numbers 1 to 6 in Figure 4. Organic resources and their transfer between farm enterprises are extremely important in small-scale farming systems, and may be grouped into common practice (Table 14). Some resources have lower quality (reduced nutrient contents) such as maize stover and are best passed through livestock (or used as bedding) and converted to manure, while others are richer in nutrients and used as sources of organic nutrients [10]. Some are actively transferred and spread or incorporated into soil, particularly manures. Others are passively transferred through intercropping, crop rotation and stubble grazing. In many cases, the best route for palatable organic resources is through livestock, even those nutrient-rich materials such as legume residues. and then efficiently utilized as fresh excreta and composted manures. This practice is consistent with farmers' needs to feed relatively large numbers of livestock on their small farms (Table 5) [11]. Quantifying these interactions is more difficult as they may require direct estimates of crop residues and repeated observations of their use.

These interactions between entry points are somewhat generalized, and do not consider some important farm and household activities. Household gardens are not included as separate, more intensively managed farm enterprise [11] but rather are grouped with root crops under Crop Diversification. Nor does this analysis consider fodder production and fallows, important options available to larger farms. Nonetheless, this paper provides needed information on farm nutrient flows, labor priorities and complementarities and tradeoffs between farm enterprises. Furthermore, additional understanding on the improvement of natural resource management is in fact nested into organic resource management and the farm biodiversity described in this study but not explicitly described.

\section{Conclusions}

A useful description of smallholder farming systems in west Kenya was constructed from a detailed household survey conducted by the N2Africa Project in 2013 [2]. These data were summarized across 291 household operations and then contrasted in terms of farm resource endowment, agro-ecological zone and household leadership. Households with less than 0.1 ha per member generate less income and experience more hunger, and should be higher priority beneficiaries of developmental research programs. The three agro-ecological zones of the west Kenya are all heavily dependent upon maize-based agriculture but otherwise have many differences in terms of farm commodities, management operations and opportunities for effective intervention. The Lake Victoria Basin is semi-humid at best and water management strategies not described in this study assume greater importance. Households led by women face several disadvantages compared to their male-led counterparts, including earning less income and endure more hunger, but have developed farm practices that make better use of available organic resources and tend to operate more diverse farms. Despite large differences in per capita resource endowment and agro-ecological zones, all of the farm households encountered during this study are poor by internationally recognized standards and diversified options of agricultural transformation are needed in west Kenya.

\section{Acknowledgements}

Data compilation services were provided by Ms. Welissa Mulei of WeRATE, Kenya. Data collection for this study was conducted by the N2Africa Project that is funded by the Bill and Melinda Gates Foundation. These analyses were conducted in support of the CGIAR Humidtropics Program West Kenya Action Site. All of this logistical support and research sponsorship is greatly appreciated.

\section{REFERENCES}

[1] Humidtropics Program. 2012. Humidtropics: Integrated Systems for the Humid Tropics (Project Document). IITA, Ibadan, Nigeria. $188 \mathrm{pp}$.

[2] Woomer, P. L., Huising, J., Giller, K. E. et al. 2014. N2Africa Final Report of the First Phase 2009-2013, www.N2Africa.org, $138 \mathrm{pp}$.

[3] Sombroek, W.G., Braun, H.M.H. and Van Der Pouw, B.J.A. 1982. Exploratory Soil Map and Agroclimatic Zone Map of Kenya. Kenya Soil Survey Report No E1. National Agricultural Research Laboratories, Nairobi. pp 56.

[4] Crowley, E. and Carter, S. 2000. Agrarian change and the changing relationships between toil and soil in Marigoli, Western Kenya. Human Ecology 28:383-414.

[5] Woomer, P.L., Bekunda, M.A., Karanja, N.K., Moorehouse, T. and Okalebo, J.R. 1998. Agricultural resource management by smallhold farmers in East Africa. Nature and Resources 34:22-33.

[6] Okalebo, J.R., Otieno, C.O., Woomer, P.L., Karanja, N.K., Semoka, J.R.M., Bekunda, M.A., Mugendi, D.N., Muasya, R.M., Bationo, A. and Mukhwana, E.J. 2006. Available technologies to replenish soil fertility in East Africa. Nutrient Cycling in Agroecosystems 76:153-170.

[7] Tittonell, P., Vanlauwe, B., Leffelaar, P.A., Rowe, E. and Giller, K.E. 2005a. Exploring diversity in soil fertility management of smallholder farms in Western Kenya. I. Heterogeneity at region and farm scale. Agriculture Ecosystems and Environment 110:149-165.

[8] Gladwin, C.H., Buhr, K.L., Hiebsch, A.G.C.H., Hilderbrand, P.E., Kidder, G., Langham, M., Lee, D., Nkendi-Kizza, P. and Wiliams, D. 1997. Gender and soil fertility in Africa. In: Buresh, R.J., Sanchez, P.A. and Calhoun, F. (eds). Replenishing Soil Fertility in Africa. Soil Science Society of America Special Publication 51, Madison, USA. pp 219-236. 
[9] Sanginga, N. and Woomer, P.L. (eds.). 2009. Integrated Soil Fertility Management in Africa: Principles, Practices and Developmental Process. Tropical Soil Biology and Fertility Institute of the International Centre for Tropical Agriculture. Nairobi. 263 pp.

[10] Palm, C.A., Gachengo, C.N., Delve, R.J., Cadisch, G. and Giller, K.E. 2001. Organic inputs for soil fertility management: Some rules and tools. Agriculture Ecosystems and Environment 83:27-42.

[11] Woomer, P.L., Karanja, N.K. and Okalebo, J.R. 1999. Opportunities for improving integrated nutrient management by smallhold farmers in the central highlands of Kenya. African Crop Science Journal 7:441-454. 